\title{
EDUCAÇÃO DE ADULTOS COMO PROCESSO CONTINUADO E PERMANENTE: UM ESTUDO DE CASO COM IDOSOS
}

\section{Continuing and permanent adult education: a case study with elderly}

\author{
Alcides Alves de Souza Filho \\ (UNEB) \\ LATTES iD http://lattes.cnpq.br/0353684132153514 \\ Antonio Amorim \\ (UNEB) \\ LATTES iD http://lattes.cnpq.br/9993429400708011 \\ Kátia Siqueira de Freitas \\ (UCSAL) \\ ORCID iD https://orcid.org/0000-0003-0984-814X
}

Informações do artigo

Recebido em 15/04/2020

Aceito em 29/04/2020

doi>:

https://doi.org/10.25247/2447-861X.2020.n249.p167-185

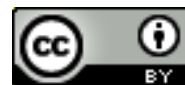

Esta obra está licenciada com uma Licença Creative Commons Atribuição 4.0 Internacional.

Como ser citado (modelo ABNT)

SOUZA FILHO, Alcides Alves de. AMORIM, Antonio. FREITAS, Kátia Siqueira de. Educação de adultos como processo continuado e permanente: um estudo de caso com idosos. Cadernos do CEAS: Revista Crítica de

Humanidades. Salvador, v. 45, n. 249, p. 167-185, jan./abr. 2020. DOI: https://doi.org/10.25247/2447861X.2020.n249.p167-185

\begin{abstract}
Resumo
O artigo trata da educação da pessoa idosa. Discute práticas e processos socioeducativos que materializam o programa voltado à Política Pública na perspectiva de educação escolar e social. Aponta a importância da Educação Continuada e Permanente na vida do idoso. Objetiva analisar os aspectos educativos que concretizam a ressignificação da vida e reconstrução de si na fase idosa, vivenciando aprendizagens e saberes no ambiente de uma Universidade Aberta à Terceira Idade (UATI), programa de extensão. Adota a pesquisa qualitativa conspecto no caráter fenomenológico, utiliza a autobiografia como dispositivo metodológico e a entrevista narrativa como geradora do corpus de pesquisa. Suporta a discussão do corpus de pesquisa nas escritas de Abrahão (2018); Freire (2006); Palomo (2006); Serra (2015); Silva (2013); Souza (2015), Souza Filho (2019), outros. Os resultados evidenciaram a evolução dos sujeitos mediante práticas educativas voltadas à subjetivação, à compreensão de "si", à reconstrução e ressignificação de "si" e à importância da educação ao longo da vida.
\end{abstract}

Palavras-chave: Educação de pessoas idosas. Processo socioeducativo. Práticas educativas.

\section{Abstract}

The article deals with the education of the aged and elderly person. It discusses the socio-educational practices and processes that focus on Public Policy from the perspective of schooling and social education. It points out the importance and impact of Continuing and Permanent Education in the life of the elderly. It focuses on the objective of analyzing the educational aspects that help elders to the reconstruct oneself by way of experiencing learning and knowledge in the environment of an University Open to the Third Age. It adopts qualitative research using autobiography as a methodological device and narrative interview as the generator of data. This work extends the research corpus in the writings of Abrahão (2018); Freire (2006); Palomo (2006); Serra (2015); Silva (2013); Souza (2015), Souza Filho (2019), others. The results showed the improvement of subject-learners employing educational practices aimed at subjectivity, the understanding of the "self", the reconstruction and reframing of the "self" and the need for lifelong learning.

Keywords: Education of the elderly. Socio-educational process. Autobiography. 


\section{Introdução}

A preocupação com o público idoso vem sendo um dos motivos de estudos e pesquisa no contexto atual. O processo da longevidade tem movido estudiosos no sentido de compreender a vida das pessoas idosas, a relevância da qualidade de vida, as necessidades expressas e sentidas, assim como o papel da educação continuada e permanente nas vidas dos idosos. Sendo assim, a melhoria nas condições de vida, em princípio, vem repercutindo no aumento demográfico do envelhecimento da população e, nessa perspectiva, requer atenção e oferta de políticas públicas que propiciem, às pessoas em geral, perceber o envelhecimento de forma natural, assim como as pessoas envelhecidas aprendam a conviver e superar as limitações impostas pela idade avançada.

No contexto da população idosa e envelhecida, o grande desafio de estar no mundo passa pela necessidade de participar de modo mais efetivo e autônomo na sociedade, diante dos paradigmas e preconceitos que permeiam as relações para com as pessoas idosas, sempre carregadas de estigmas. Pois bem, estar vivenciando 60 anos ou mais pode significar viver uma fase bela e complexa da vida. Mas, o enfrentamento requer superação e luta pela garantia e manutenção de direitos sociais e constitucionais.

Os desafios para ampliar o conjunto de avanços construídos mostram a insuficiência de ações públicas, justificando as lutas organizadas pelos movimentos sociais e organizações não governamentais, requerendo intervenções voltadas a atender carências da pessoa idosa na saúde, no enfrentamento de problemas sociais nos seus vários contextos regionais, na legislação, dentre outros.

Partimos desse enfoque introdutório para discutir sobre a necessidade e importância da educação para a pessoa idosa no modelo de educação que diligencia dar continuidade ao processo de obtenção de novos conhecimentos adotando uma perspectiva socioeducativa. Desenvolvemos o estudo contando com os estudantes, numa faixa etária acima dos sessenta $\operatorname{anos}^{1}$, todos de uma Universidade Aberta à Terceira Idade- UATI ${ }^{2}$, programa de extensão Nesse contexto, tomamos a educação de adultos como o viés para o estudo das práticas

\footnotetext{
1 Projeto de Lei N. 5383/2019 em tramitação aumenta para 65 a idade a partir da qual a pessoa é considerada idosa.

2 Evitamos contextualizar a UATI para preservar a identidade da instituição.
} 
socioeducativas, pois, historicamente, essa modalidade de ensino tem assumindo um papel importante enquanto espaço de inclusão social e educacional dos idosos.

Diante da importância do tema em estudo, recorremos às narrativas (auto) biográficas, tencionando compreender as questões da educação da pessoa idosa. Nesse sentido, perceber quão necessárias são as políticas públicas para atender o público idoso, parcela da nossa sociedade que, por vezes, sofre o processo de exclusão social e educacional.

Por se tratar de um pleito importante no campo da educação, é necessário investir em alternativas técnicas e tecnológicas, bem como em pessoal qualificado nos diversos campos do saber para contribuir com a população idosa, proporcionando-lhe suprir as necessidades que a condição humana exige, valorizando saberes e experiências de vida de cada pessoa idosa.

O espaço para a educação de idosos - é um meio de troca de experiências e se caracteriza, também, por um viés socioeducativo, sendo oferecido pela UATI. Por essa razão indagamos: qual a relevância, para a vida do idoso, da educação continuada e permanente realizada em uma Universidade Aberta à Terceira Idade?

Em linhas gerais, a discussão dessa questão busca responder e dar sentido à criação de espaços socioeducativos, em face à pouca opção de "lugares" dedicados à atenção e ao atendimento ao público idoso, perspectiva relacionada direta e principalmente ao descaso do poder público.

O objetivo geral está voltado para a análise de aspectos educativos que concretizam a ressignificação da vida e reconstrução de si na fase idosa, a partir de aprendizagens e saberes vivenciados no ambiente socioeducativo da UATI. Para nortear a discussão, elencamos objetivos específicos visando: identificar o significado e a importância da educação para a pessoa idosa; compreender as práticas educativas da UATI que levam o participante a uma nova visão de mundo; estabelecer relação entre o processo de educação escolar e social na promoção da subjetivação, na ressignificação de vida e na reconstrução do próprio sujeito idoso.

A UATI tem como parte de sua missão contribuir com o processo de aquisição de novos conhecimentos, com a valorização e o resgate das identidades de homens e mulheres a partir dos sessenta anos, além de servir como referência para educadores de adultos na tratativa das questões das práticas educativas e metodológicas relacionadas com os idosos na escola. 
É possível perceber conflitos na inserção das pessoas idosos nos programas educacionais. Há os que buscam se inserir socialmente através da educação, apresentando dificuldades na aprendizagem com ou sem o domínio do código da escrita e da leitura. Há aqueles que ainda estão fora da escola vivendo numa condição de invisibilidade e exclusão.

O artigo está distribuído em introdução, na qual caracterizamos a temática voltada para a educação da pessoa idosa, o problema, os objetivos; a trajetória teórico-metodológica; a caracterização dos sujeitos e do local da pesquisa; a discussão do processo socioeducativo e as possibilidades da educação continuada; a conclusão; e, por fim, as referências.

\section{Trajetória teórico-metodológica}

Adotamos como suporte teórico as discussões de Abrahão (2018), Brandão (2002); Freire (2006); Hillman (1997); Linde (2004); Oliveira (1999) Palomo (2006); Pinto (2001); Poirier et al (1999); Rodrigues (1991); Serra (2015); Silva (2013); Souza (2015) e Souza Filho (2019).

Para que subsidiassem o estudo frente à problemática, visando entender os fenômenos, envolvendo os processos de educação e aprendizagens da pessoa idosa, adotamos uma sequência de procedimentos metodológicos atinentes à pesquisa aplicada, pois a

[...] opção pela pesquisa aplicada surge a partir da necessidade em avançar nas pesquisas e na aplicabilidade dos produtos oriundos delas, uma vez que consiste na investigação original concebida pelo interesse em adquirir novos conhecimentos, bem como "resolver problemas ou necessidades concretas e imediatas" (SOUZA FILHO, 2019, p. 40).

Realizada a opção pela pesquisa aplicada, visto o significado e a importância que essa tipologia de pesquisa encerra, lançamos o olhar aos sentimentos apresentados pelos sujeitos da pesquisa, o que, segundo Barros e Lehfeld (2000, p. 78), tem "[...]o objetivo de contribuir para fins práticos, visando à solução mais ou menos imediata do problema encontrado na realidade".

Em seguida,

[...] abarcamos o sentido fenomenológico tangente ao significado e sentimento trazidos pelos idosos, enquanto sujeitos do estudo, diante daquilo que propomos como foco de investigação, permitindo perceber o dinamismo das situações, o que não seria possivel atingir se não estivéssemos envolvidos no contexto do estudo. Sendo assim, a nossa perspectiva, ao adotarmos a abordagem qualitativa com os fundamentos da 
fenomenologia, foi de não só captar a aparência do fenômeno, mas adentrar nas características mais importantes que explicassem a sua origem, relações e mudanças, bem como deduzir as consequências (SOUZA FILHO, 2019, p. 40).

Destarte, a abordagem qualitativa da pesquisa, no sentido destacado da fenomenologia, permitiu perceber os sujeitos, sua subjetividade e o estudo tangente à compreensão e interpretação dos motivos que mobilizam idosos para educação, vida social e expectativas sobre novas experiências.

Seguindo o entendimento de Marli André (2015), esse tipo de abordagem possibilita examinar o mundo como ele é experienciado, tendo no comportamento humano o parâmetro individual de cada pessoa, ou de um pequeno grupo de pessoas, a partir do que tomam como verdade, valorizando a indução e assumindo que fatos e valores, que estão intimamente relacionados, condicionam o pesquisador visto à impossibilidade de uma postura neutra enquanto participante do processo.

Buscando a composição do corpus de pesquisa, ancoramo-nos na autobiografia, enquanto dispositivo metodológico que - segundo Souza (2007, p. 65), citando Josso (2004) - acata a "[...] subjetividade como modo de produção do saber e à intersubjetividade como suporte do trabalho interpretativo e de construção de sentido para os auto-relatos".

A opção pela entrevista narrativa no contexto da investigação, enquanto dispositivo da pesquisa, ampliou o entendimento do método que potencializou o aprofundamento da investigação a partir das combinações entre história de vida e contexto sócio-histórico e socioeducacional. Possibilitando, assim, a compreensão dos sentidos que formam as crenças e os valores norteadores das ações dos sujeitos, ampliando a credibilidade no corpus de pesquisa, pois, no entendimento de Poirier et al (1999, p. 108), trata-se de "[...] um material qualitativo construído por um conjunto de histórias de vida, de sujeitos saídos de um universo populacional nitidamente definido", que subsidiaram a autobiografia.

O questionário, também como dispositivo da pesquisa, se apresentou como ferramenta para construir o perfil sociobiográfico e de consulta com relação à participação nos relatos das histórias de vida.

A partir de 52 questionários aplicados, estabelecemos a linha de corte para determinar aqueles que gostariam de participar das entrevistas, observando a disponibilidade de tempo e a possibilidade de estar no local da pesquisa nos períodos programados, frente aos compromissos particulares dos selecionados. Desta forma, foi possível obter uma amostra 
do público idoso da UATI e seguir com a construção do perfil sociobiográfico, a análise de outras questões pertinentes ao UATI e ao programa socioeducativo.

Os sujeitos da pesquisa foram 11 idosos de ambos os sexos, o mais novo com 63 anos de idade e o mais velho com 82. Todos frequentam o programa de extensão da UATI- em uma universidade pública na cidade do Salvador - BA, tomada como lócus da pesquisa. Os nomes dos participantes, apresentados no Quadro 1 são fictícios para preservar a identidade dos mesmos.

Quadro 1 - Dados sociobiográficos dos sujeitos

\begin{tabular}{|c|c|c|c|c|c|c|}
\hline \multicolumn{7}{|c|}{ Dados sociobiográficos dos sujeitos } \\
\hline Nome & Sexo & $\begin{array}{l}\text { Idade } \\
\text { (anos) }\end{array}$ & Escolaridade & Bairro onde reside & $\begin{array}{l}\text { Situação } \\
\text { social }\end{array}$ & Como chegou a UATI \\
\hline Analú & Fem. & 69 & Pós-graduada & Rio Vermelho & Aposentada & Através do Prepara-se \\
\hline Margô & Fem. & 75 & Graduação & Imbui & Aposentada & Indicação de familiar \\
\hline Eva & Fem. & 67 & Segundo Grau & São Rafael & Aposentada & Indicação de geriatra \\
\hline Alves & Fem. & 63 & Segundo Grau & Pirajá & $\begin{array}{l}\text { Em } \\
\text { atividade }\end{array}$ & Indicação médica \\
\hline Neto & Mas. & 79 & Segundo Grau & Pernambués & Aposentado & Informação de amiga \\
\hline Diú & Mas. & 73 & Primeiro Grau & Don Avelar & Aposentado & $\begin{array}{l}\text { Informação da } \\
\text { instituição }\end{array}$ \\
\hline Yara & Fem. & 65 & Graduação & Pau da Lima & Aposentada & Informação de amiga \\
\hline Pimenta & Fem. & 71 & Segundo Grau & Águas claras & Aposentada & $\begin{array}{l}\text { Funcionário da } \\
\text { universidade }\end{array}$ \\
\hline Barreto & Fem. & 82 & Segundo Grau & Imbui & Aposentada & Indicação de familiar \\
\hline Valdo & Mas. & 67 & $\begin{array}{c}\text { Pós- } \\
\text { Graduação }\end{array}$ & Imbui & Aposentado & $\begin{array}{l}\text { Indicação de outra } \\
\text { aluna }\end{array}$ \\
\hline Solange & Fem. & 68 & Segundo Grau & Cabula & Aposentada & $\begin{array}{l}\text { Indicação de outra } \\
\text { aluna }\end{array}$ \\
\hline
\end{tabular}

Fonte: Elaborado pelos autores a partir dos dados sociobiográficos, 2019.

Universidade Aberta à Terceira Idade (UATI) é um programa de extensão universitária de uma universidade pública, caracterizado como uma rede não formal de educação continuada, voltado a atender às pessoas idosas de ambos os sexos e de qualquer nível socioeducacional, cuja faixa etária seja igual ou superior a sessenta anos.

Tomamos a UATI como referência para a pesquisa, focalizada no estudo do modelo de educação socioeducativa, por privilegiar e intensificar ações que valorizam os saberes, desenvolvem novas competências e cultivam a heterogeneidades de ideias, incentivando o sentimento de identidade e pertencimento.

A abrangência da UATI contempla pessoas idosas residentes nos bairros de Salvador e de toda região metropolitana. Aqueles que residem em localidades mais distantes têm 
problemas com questões que envolvem o sistema de transporte, por vezes, impossibilitando o deslocamento, pois nem todos têm a sua disposição veículo automotivo próprio ou de algum membro da família e, mesmo quando o têm, fica onerosa a dinâmica de locomoção. Assim, Diú comentou (entrevista):

"Tenho três filhas e quatro filhos homens, todos têm carro, um deles não sai de carro. De vez em quando eu pego o carro e venho pra cá, fica muito caro. Outro dia, quando viajamos para Maceió peguei um taxi que deu trinta reais. Se tivesse dois ou três que morasse em Don Avelar ficava melhor cada um pagava dez ou quinze. Quando eu saio assim eu pego Uber ou táxi e eu pago só!"

A dificuldade de deslocamento foi um dos aspectos levado em consideração para estabelecer a amostra do público da pesquisa. Para tanto, elaboramos o questionário consulta no sentido de conhecer nuances da dinâmica de locomoção e, através dele, também obter, com base no critério de adesão, participantes das oficinas de Identidade e Memória; Psicologia do Envelhecimento; e Fotografia e Vídeo, que optassem por participar na pesquisa.

\section{Os participantes da pesquisa e suas especificidades}

A partir da visão mais ampliada sobre os participantes da pesquisa, entendemos estar trabalhando com uma amostra de público "[...] heterogêneo, com seus problemas psicossociais e econômicos, com uma visão de mundo imbricada na esperança de dias melhores, atuantes dentro de uma proposta de ação educativa de caráter permanente, sob a ótica da Pedagogia Social" (SOUZA FILHO, 2019, p. 62).

Esse foi também considerado como o retrato psicossocial dos idosos que frequentavam a UATI, constituindo uma parcela do contingente da população de idosos reconhecidos oficial e socialmente por já terem atingido a idade dos 60 anos. Trazia consigo o desejo de manter a continuidade do processo de aprendizagem, tencionando ampliar conhecimentos e renovar saberes: a requalificação de si.

Alguns ansiavam ampliar a proficiência na decodificação dos códigos linguísticos, conjecturando manter-se no ritmo de continuar a exercer as atividades básicas do seu cotidiano, acreditando ser a educação "[...] um ato de recriação e ressignificação de significados, onde o fio condutor da alfabetização visa à libertação social e política" (FREIRE, 2011, p. 35). 
Tradicionalmente, programas de escolarização de pessoas jovens e adultas tinham, na sua maioria, alunos oriundos do campo, trabalhadores domésticos, outros, marcados fortemente pelo analfabetismo e pela falta de oportunidades no processo formativo. Contudo, há outros objetivos que levam a pessoa idosa às fileiras das salas de aula.

Isto fica explicitado na fala de Yara, no excerto da entrevista narrativa, ao afirmar que estar na escola é uma forma de conseguir algo necessário à sua realização pessoal:

"[...] viver e transformar a sua cultura e junto com a educação ela completa intelectual, social e familiar esse idoso vai construindo sua vida gradativamente, vivendo o momento real, cada idade com a sua realidade e vivendo esse momento com a possibilidade real. Se hoje eu não posso descer de paraquedas, então que eu mude meu foco já que eu não tive condições de fazer antes [...]".

Essa percepção está contida na fala de outros participantes, como, por exemplo:

"[...] a educação é à base de tudo porque, aqui, sem a educação acho que é impossível a pessoa viver" (Valdo, entrevista);

"[...] a pessoa educada é melhor para ela viver, ela sabe levar as coisas muito bem. Lá fora os problemas pela sua formação, pela sua educação, ela recupera e passa pelas barreiras. Ela sabe viver e não leva as coisas com violência, ele tem paciência, ele tem que ter muita paciência e a educação ajuda a você ter paciência" (Pimenta, entrevista);

"[...] me completa, entendeu? Eu me sinto muito bem quando venho praquí. Aprendi muita coisa nova, aprendi muito conteúdo, tem coisa que eu não sabia e que hoje eu já sei" (Alves, entrevista).

Muitas dessas senhoras e senhores fogem da rejeição e negação de suporte familiar, buscam retornar à escola - lugar de trocas e vivências - onde é possível vencer as fragilidades individuais muitas vezes reconhecidas pelo próprio sujeito. O grupo, atendido pela UATI, goza de uma relativa autonomia, mas também apresenta carências que traduzem aspectos nevrálgicos na vida das pessoas: a falta de afetividade e de acolhimento.

Destarte, para exercer a função acolhedora, a instituição tem entre seus docentes profissionais capacitados para atender aqueles que "[...] chegam com um nível de energia muito baixo, desanimados, carentes e deprimidos, [...] propiciando ao idoso ampliar sua capacidade vital com criatividade, prazer e alegria num processo de reintegração com a vida" (GUERRA, 2012, p.101).

De forma geral, a categoria de público que frequenta a UATI representa uma proporção da população de idosos, tidos e reconhecidos oficialmente por já ter alcançado os 
60 anos de idade e, ainda assim, mantém o desejo de dar continuidade ao processo de ampliar conhecimentos. Na amostra, todos tiveram acesso à decodificação dos códigos da escrita e da leitura.

A importância da educação continuada e permanente para atender às pessoas idosas que vivem dificuldades para exercer as atividades básicas do seu cotidiano é incomensurável. Nesse sentido, a educação é pensada como "[...] um ato de recriação e ressignificação de significados, onde o fio condutor da alfabetização visa à libertação social e política" (FREIRE, 2011, p. 35).

No âmbito dessa discussão, tratamos adultos com suas especificidades, carências, expectativas, problemas psicossociais de resistências, desconfianças.

\section{Ressignificar a vida e reconstrução de si na ótica do processo sócioeducativo}

A educação continuada e permanente no modelo socioeducativo, desenvolvido pela UATI, abarca o recorte sócio-histórico da educação ao estabelecer uma conexão entre o caminho de dificuldades percorrido pelos que recorrem à educação como via de desenvolvimento, mesmo tendo vivenciado grandes barreiras na trajetória da sua educação, e, mais adiante, tendo encontrado nos estudos a oportunidade de trilhar o caminho formativo. Evidenciamos esse cenário com o excerto narrativo de Alves:

"[...] quando comecei a estudar. Já tinha uns dez anos ou mais. Aí estudei, naquele tempo não era avançado, fiz até a primeira série. Depois tinha uma escola da prefeitura de outra prima minha, assim numa fazenda, aí estudei até a segunda série, hoje é o segundo ano. Depois parei, não estudei mais, foi quando minha mãe morreu e eu fui morar com minha irmã na cidade para eu estudar, mas naquele tempo quando se tinha 12 anos não se matriculava mais. Eu tinha a maior vontade de estudar, mas como eu estava com a idade avançada, então eu não pude estudar na escola. Mas eu nunca parava de estudar, todo livro que via ficava lendo" (Alves, entrevista).

Observamos, no excerto, fragmentos da história de vida, uma trama comum e semelhante nas histórias de grande parte dos adultos que buscam a UATI. Passagens semelhantes foram constantes nas narrativas apresentadas pelos sujeitos, devido à trajetória de vida, contextos histórico, social e econômico.

Pensada a educação no modelo socioeducativo, Souza Filho (2019) situa a discussão em torno de algumas das questões fundamentais e elementares na análise do contexto social e da vida da pessoa idosa, tais como: 
[...] a aceleração do aumento populacional de idosos; o interesse pelas pesquisas com o idoso; a mudança de paradigmas do envelhecimento; os pressupostos sobre o envelhecimento como um processo multideterminado e heterogêneo; a concepção de desenvolvimento e aprendizagem por toda a vida; a capacidade de adaptação diante de novas experiências (SOUZA FILHO, 2019, p. 74).

Essa afirmação requer pensar a educação socioeducativa para um público idoso com características próprias. Para tanto, precisamos analisar aspectos relevantes que definem a necessidade de incremento educacional nessa categoria da sociedade. São questões presentes em estudos que envolvem a plasticidade de adaptação ao longo do processo de envelhecimento e de mudança da capacidade humana e, portanto, requer perceber a importância e necessidade de observarmos o contexto social imbricado com as trajetórias narradas pelos participantes da pesquisa, assim exemplificadas:

"[...] eu estudei até o terceiro ano primário, cheguei aqui pra participar da aula de história, aí achei que eu devia pegar mais um pouco de conhecimento. Aí voltei para a escola primária (fundamental) e depois conclui o primeiro grau, a oitava série. - Aí o professor perguntou: por que não continua para concluir o segundo grau? Respondi: Aqui pra mim já está bom, porque eu não vou trabalhar mais, foi só para ter um pouco de conhecimento". (Dionísio, entrevista).

Está evidenciado, pois, o papel e a importância da educação continuada e o quanto vem contribuindo para a educação da pessoa idosa com iniciativas e processos socioeducativos voltados para a inclusão dos mesmos. Sendo assim, a educação com inclusão, enquanto elemento que converge para o ideário no sentido da cidadania, promove equidade e justiça social na tessitura da sociedade, no entendimento e na compreensão do processo construtivo e evolutivo da educação socioeducativa.

Portanto, o fenômeno da educação é "[...] um fato social em que pese o interesse da comunidade em integrar todos os membros a um modelo social vigente (relações econômicas, instituições, usos, ciências, atividades, etc.)" (PINTO, 2001, p. 30). Ou seja, propicia integração e inclusão social.

Desta forma, o movimento de busca pela inclusão social da pessoa idosa sempre esteve ancorado na bandeira da educação, pois "[...] os idosos têm a concepção da importância do estudo na vida do cidadão [...]" (SERRA, 2015, p.172), servindo como premissa importante para o processo de reeducação e ressignificação da vida para o enfrentamento ao envelhecimento. 
"Conquistar o segundo grau melhorou de mais a minha vida, tá doido! Olhe, eu falava errado quando comecei a estudar. Quando eu recomecei a estudar, esses ignorantes [...] dizendo: "pra que tu tá estudando, tu não vai trabalhar mais mesmo"! - Então disse: sabe pra que é? Saber mais que seu dono e outra coisa eu estou estudando pra não estar falando coisas erradas e aprender cada vez mais, saber se desenvolver e tudo" (Alves, entrevista).

Evidenciando, no fragmento narrativo citado, o sentido da educação manifestado por Serra (2015) revela um movimento de busca por educação que não se apresentava como um caminho para a capacitação produtiva, construção do poder aquisitivo e de reconhecimento socioeconômico, mas como forma de ressignificar a vida e os hábitos, antes tidos como obstáculo para o desenvolvimento social. Segundo reitera Brandão (2002),

[...] estuda-se e deve-se estar sempre aprendendo, porque se é desde sempre uma pessoa cidadã, ou em construção da cidadania desde a tenra infância, ao longo de uma sempre contínua descoberta e recriação de si mesmo com, para e através de outros. Para realizar isto é que se estuda dentro e fora da escola - e se deve estar sempre aprendendo. Ao longo de toda a vida, a educação destinada à comunicação, e não ao trabalho destinado à produção, deve ser a experiência de identidade de cada um de nós (BRANDÃO, 2002, p. 79).

Conduzida a discussão pelo enfoque autobiográfico, a educação se apresenta como base para a formação complementar da pessoa idosa, no sentido de abarcar as nuances da ressignificação e reconstrução de si, frente aos desafios e a necessidade do desenvolvimento de habilidades ao longo da vida, como proposta de manutenção do envelhecimento saudável e o firmamento da cidadania.

Sendo assim, a educação continuada e permanente da pessoa idosa incorpora uma forma eficaz de promover a inclusão e articulação com a sociedade, "[...] aprimorando continuamente o processo inclusivo com conquistas e superação, abarcando mudanças de hábitos e opiniões, conscientização e mudança de realidade social, a partir das novas práticas e participação nas instituições educacionais" (SOUZA FILHO, 2019, p. 93).

Nesse sentido, o processo socioeducativo comunga com a concepção de política pública que oportuniza a possibilidade da inclusão social, certo de que

Inclusão Social é oferecer aos mais necessitados, oportunidades de acesso a bens e serviços, dentro de um sistema que beneficie a todos e não apenas aos mais aptos. A inclusão torna-se viável somente quando, através da participação em ações coletivas, os excluídos são capazes de recuperar sua dignidade e conseguem - além de emprego e renda - acesso a moradia 
decente, facilidades culturais e serviços sociais como educação e saúde, por exemplo. (SILVA, 2013, p.44).

Portanto, através dos relatos (auto) biográficos, em forma de recorte das entrevistas narrativas, podemos conceituar a inclusão social como satisfação dos sujeitos com o espaço socioeducativos. Da mesma forma, a narrativa de si:

[...] traz as marcas inevitavelmente ambivalentes dos usos dos quais é o objeto, das funções que ela é obrigada a investir: às vezes um suporte para a construção pessoal, às vezes um objeto público formatado e reificado; às vezes lugar de elaboração de experiência singular, às vezes lugar de conformação; às vezes um ato de resistência; às vezes um ato de lealdade; às vezes uma narrativa que faz um "sujeito" ganhar vida, às vezes uma narrativa que subjuga (ABRAHÃO; CUNHA; VILAS BOAS, 2018, p.9o).

Concomitante à expressão dos autores e com a análise compreensiva-interpretativa e política do sentido em Souza (2014), entendemos a ressignificação e reconstrução de si próprio, ao considerar que o "[...] movimento de construção/produção das narrativas foi permeado das ações de lembrar, narrar e refletir sobre histórias e fatos e, principalmente, o de recordar elementos construtores da formação individual e social" (SOUZA FILHO, 2019, p.110).

Então, nos debruçamos sobre o significado da instituição que trabalha com o processo socioeducativo. Mapeando alguns fragmentos das narrativas, deparamo-nos com os seguintes entendimentos:

"Quando chego aqui esqueço algumas coisas. Coisas que não vale a pena me lembrar [...]. Eu acho que a UATI é inovadora porque a cada dia a gente vai descobrindo uma coisa, você vai descobrindo! E só o fato de você chegar aqui e encontrar tanta gente, pessoas idosas que não quer sair daqui [...]" (Eva, entrevista).

"[...] é uma aliada na superação de tabus, de preconceitos, acho que é isso aí! Eu não saio daqui! Agora vamos pra frente, [...] porque eu acho que ela estimula a integração, a você viver e ressignificar a vida, a não se colocar como vítima e ficar ali no chororô" (Analú, entrevista).

"[...] é viver a minha segunda casa. Aqui eu consegui muitas amizades, depois que entrei aqui melhorei muito! [...] Me sinto bem quando estou aqui, apesar de que 0 tempo é pouco" (Diú, entrevista).

"[...] meu sentimento é de prazer. Sempre me sentindo bem em um lugar em que você não se estressa. Então vem pra cá! E nesse vim é bom, tanto quem tem conhecimento transmite como aprende. Aqui é o lugar onde o professor ensina e 
aprende; no mínimo ele aprende com a experiência que têm os alunos dele" (Neto, entrevista).

"Meu sentimento em relação à UATI é um sentimento de um programa levado para a área pública, é um sentimento de acolhimento, é um sentimento de troca, porque dou o respeito e ao mesmo tempo recebo. A compreensão que eu dou para as outras pessoas eu também recebo, a gente troca muito, né!" (Yara, entrevista).

As narrativas enalteceram o sentido da educação. Corroborando com os posicionamentos, Analú (entrevista) fez a seguinte assertiva:

"Eu acho que o pilar central é a educação, seja lá em que idade, para mim uma pessoa educada do ponto de vista mais global tem alegrias, tem felicidades, tem saúde, [...] o que eu vejo lá é melhor qualidade de vida e alegria, né! [...], mas a satisfação é que faz todo mundo repetir. Eu mesmo já repeti o ano passado e vou repetir esse ano com fé em Deus!"

Frente a um espaço de construção de novas identidades, transitando desde a necessidade de ocupar o tempo com algo produtivo até a formação digital tão necessária nos dias de hoje, a busca pela educação continuada e permanente pode ser vista e contemplada no atendimento humanístico dispensado pela instituição, expressa na assertiva "eles transcendem a questão do conceito de idoso meramente convencional" (Analú, 2019, entrevista), promovendo a satisfação e a alegria.

A luta pela manutenção do espaço e as reivindicações por melhorias sugerem manter e ampliar o espaço de construção educacional para as diferentes identidades, mas com uma identidade institucional baseada no programa socioeducativo. Por conseguinte, essa vertente educacional abre possibilidades para que os sujeitos alcancem a autonomia que thes permite "[...] desconstruir essa coisa do certinho, do paradigma, do script que foi dado pra vida" (Analú, entrevista) e descobrir "[...] coisas maravilhosas que o mundo e ela estão aí nos oferecendo" (Margô, entrevista).

Versando sobre a reconstrução e ressignificação de si, discutir a proposição de escola para a pessoa idosa propõe a visão de escola propositiva que vai ao encontro de uma educação de integração entre as pessoas da mesma faixa etária ou semelhante, abrangendo trajetórias de vida, experiências, perspectivas e sonhos. Esse contexto social e histórico promoveu o entendimento de que "[...] uma escola para adultos é, sem dúvida, um lugar ideal para estimular as pessoas idosas, visto ser um espaço que contribui para a educação de todas as idades" (ANDRADE, 1996, p. 245). 
Tem sido esse o movimento: oportunizar à pessoa idosa ressignificar o sentido da vida com autonomia, com o pensamento e o olhar projetado para "si". Vislumbrando a reconstrução de "si", ser outro ou outra com novos horizontes em busca de novas experiências. Souza (2015) enfatiza que o processo de transformação gerado pela escola e, consequentemente, pela educação leva os sujeitos a deixarem de ser

[...] compreendidos como aqueles a quem falta algo, a que precisa formar, iluminar, informar. Não se trata de um pensamento único, da busca pelo consenso, pela harmonia. Está em jogo, antes, o conflito, a negociação, a discussão como ingrediente para o pensar, o criar, o imaginar possibilidades e saídas ainda não pensadas, tentadas, experimentadas (SOUZA, 2015, p. 115).

Diante do exposto, harmonizar o cotidiano dos sujeitos preenchendo lacunas, concretizando sonhos, caminhando para alternativas não tentadas, no sentido de ressignificar conceitos antes estabelecidos, remete ao lugar, ao papel e à importância dos processos formativos. Neste sentido,

Dialogar sobre o lugar no contexto das experiências vividas, os sentidos, significados e representações que emergem das situações vivências, os processos formativos advindos do interagir com o outro exige do pesquisador um olhar sensível e criterioso que o possibilite compreender os significados deste lugar para o processo de subjetivação e construção de identidades (LIMA, 2018, p. 94).

O diálogo estabelecido entre os momentos de vivências e experiências com a compreensão do "lugar" e do caminhar demarca o espaço educativo, a qualidade do desenvolvimento cognitivo e social disseminado pelo Programa, com um caráter de subjetivação, construção de identidades e ressignificações de conceitos. Para tanto, os sujeitos precisam perceber suas fragilidades e carências e buscar alternativas aderentes a sua condição como manifestou uma das entrevistadas:

Se botar uma coisa para eu fazer um comentário, eu não faço o comentário! Eu brinco muito, mas se for pra falar algo sobre alguma coisa e para muitas pessoas, pronto! É um bloqueio mesmo que eu tenho! Isso não me impede de conversar, sou falante como que, mas eu achava que devia fazer uma coisa melhor pra mim, falta fazer alguma coisa por mim. Eu preciso vencer e aí eu compro um monte de livros e os livros vão ficando em casa guardados (Eva, entrevista).

Ao reconhecer suas limitações, ela manifesta sua reconstrução ao promover alternativas, visando ao avanço cognitivo, certamente, reverberado no social. Nesse manifestar, diante das necessidades aparentes, o descolamento das vaidades, ou mesmo da 
vergonha, estabelece uma aproximação com o processo educativo quando não "[...] há possibilidade de uma relação de dominação, pois implica uma relação aberta, horizontal, ou seja, exige do educador e do educando um respeito mútuo, uma atitude de compreensão, de aceitação e principalmente de humildade" (SERRA, 2015, p. 182).

O trabalho, para vencer as dificuldades, se projeta para além do campo das ações empreendidas, estende-se a todos que articulam a aprendizagem - os professores da instituição - tanto no sentido individual quanto no coletivo, com estratégia de trabalho objetivando a participação no processo de aprendizagem por meio do diálogo, definindo e escolhendo o desejado para discutir e aprender.

A prática do diálogo presente nesse modelo de ensino/aprendizagem favorece a aquisição e inserção de novos conhecimentos, distanciando-se do modelo de educação bancária e conteudista. A dialogicidade compreende "[...] processos de ensinar, de aprender, de conhecer, não transforma este quefazer em algo triste [...]" (FREIRE, 2006, p. 37), gerando um grau de satisfação, reconhecimento e alegria. Outros participantes corroboram esse entusiasmo com os seguintes posicionamentos:

"Eu penso que as práticas são construtivas, elas são adequadas à idade [...]. Então essa prática [...] acho que isso enriquece, favorece e eu vejo que as técnicas de sala de aula são técnicas comuns que todo mundo faz, que todo mundo já está acostumado a conviver, mas muito fácil de ser administrada pelo aluno" (Yara, entrevista).

"[...] eu acho assim, que as visitas técnicas são muito interessantes, [...] sai da sala de aula. Essa última visita então, no Campo Santo, foi uma desconstrução total, não é? E pessoas que estavam reagindo que não queria ir porque era cemitério. Então, elas saíram acrescidas culturalmente. Eu acho que o ganho maior é você desconstruir [...], para mim, a minha conclusão ali foi muito boa" (Analú, entrevista).

"É uma prática humana, vê as nossas capacidades, não exige nada além da nossa capacidade e facilita a nossa aprendizagem. Quando temos qualquer dúvida, perguntamos, quer seja trabalho manual ou não, eles nos explicam com muita dedicação e atenção para que nós idosos nos sintamos assim à vontade" (Neto, entrevista).

Não raras vezes, os sujeitos passaram pelo redirecionamento de objetivos e valores, aspectos importantes no movimento de reconstrução de si. Essa trama se tornou importante diante do significado da busca pelo desejado, da escolha de novos rumos a seguir e de rever elementos basilares no processo da formação.

"O fato que mais marcou minha caminhada foi que desenvolvi, já viajo com minhas filhas, assim como viajei para Buenos Aires, fui até o Uruguai. As coisas que falava já entendia porque estudei espanhol, não falo espanhol, mas se eu pegar o livro eu falo espanhol. Eu tenho dicionário, eu tenho tudo porque quando eu não sei eu vou no dicionário. O pessoal lá no interior diz: 'quando eu ficar na idade quero ser igual à Maria'. Porque eu não me entrego 
por besteira não. Eu me desenvolvo mesmo, o que mais eu gostei e que muitas coisas eu aprendi aqui" (Barreto, entrevista).

A narrativa de Barreto apresenta o real estado do seu crescimento a partir dos conflitos e do reconhecimento de suas fragilidades. Por isso, "Propõe-se considerar, então, que o conflito é o que mobiliza o indivíduo rumo ao conhecimento de si, ou seja, retira-o da inércia do tempo racional "canônico" da consciência fazendo com que busque as variantes de si que, por permanecerem desconhecidas, apresentam desrazão" (PALOMO, 2006, p.68).

Já Solange passou pela valorização de suas potencialidades, pela não acomodação para dar sentido a sua existência e valorização da própria vida, vez que não encontrou prazer e sentido para aquela experiência, bem como o significado para sua existência. No sentido da existência, há de se considerar o tempo: passado e presente, como "as lentes pelas quais podemos ver e vivenciar [...] o espaço necessário para explorar o significado das nossas vidas e para reconstruir as nossas relações intra e extrafamiliares" (LIND, 2004, p. 2).

Descobrimos sentido na construção de vínculos afetivos, quando nos preenchem. Sendo assim, o percurso da nossa existência está conectado ao sentido da vida: o ato de viver. Com a chegada da fase idosa, buscamos, ainda, mais sentido para a vida, evitando cair no niilismo. Nesse sentido, Hillman (1997, p.55) apresenta o posicionamento de um dos seus estudados:

Eu me busco e me assusto ao perceber a matéria pela qual sou constituído... fico apático... deprimo, soluço esqueço. Não me reconheço. Erro. Acerto. Disfarço. Confio e desconfio de mim... Olho para trás e o tempo desvela uma história em que acumulei dores e disfarcei saberes sobre mim, que se mostravam incompatíveis com minhas aspirações heroicas. Como encarálas?

Hillman (1997) comenta a autorreflexão e trajetória de vida de um dos seus colaboradores ao perceber ter vivido acertos, erros, equívocos, paixões e humores com as recordações das vivências e experiências de vida. Isso fortalece a pessoa a reencontrar o seu caminho e poder seguir em frente, na busca por esperança e realizações pessoais e profissionais.

\section{Perspectivas reveladas}

Durante o estudo, observamos situações de negação da educação da pessoa idosa e dos processos socioeducativos necessários para atender algumas necessidades antepostas 
para a completude do ser. O contexto discutido mostrou a importância do programa socioeducativo, promotor de educação centrada nas necessidades para que os sujeitos possam viver com autonomia e bem-estar.

As práticas educativas adotadas no processo de educação continuada da pessoa idosa no programa socioeducativo possibilitam avanços educativos e sociais, levando-as a contemplar uma nova visão de mundo.

As entrevistas narrativo-biográficas, além de servirem de dispositivo metodológico na construção do corpus da pesquisa, contribuíram para a aproximação com as histórias de vida dos participantes tangente ao entendimento, sentido e importância de continuarem os estudos, bem como pelas singularidades das oralidades e expressão de afetividade sobre o espaço educativo.

A busca contínua e permanente por aprendizagens constrói um sentimento de subjetivação no idoso, bem como o processo de aceitação de "si", da consciência de "si", e o desejo de perseguir a ressignificação e reconstrução de "si" com novas aprendizagens ao longo da vida.

Definida a Educação Continuada e Permanente como sendo um conjunto de atividades e ações educativas com fins de atualizar o sujeito a partir da aprendizagem e das ações educacionais, surgem outros fatores que influenciam no conhecimento e nas práticas socioeducativas, com isso, desenvolve nos sujeitos o sentimento e sentido de ressignificação da vida e da reconstrução de si.

\section{Referências}

BARROS, Aidil de Jesus Paes; LEHFELD, Neide Aparecida Souza. Projeto de pesquisa: propostas metodológicas. Petrópolis: Vozes, 2000.

BRANDÃO, Carlos Rodrigues. A educação popular na escola cidadã. Petrópolis: Vozes, 2002.

BRASIL. Lei de Diretrizes e Bases da Educação Nacional. Lei número 9394, 20 de dezembro de 1996.

FREIRE, Paulo. A educação na cidade. 7. ed. São Paulo: Cortez, 2006.

HILLMAN, James. Re-visioning Psycology. New York: Harper Perennial, 1997.

LIND, W. A importância dos rituais familiares na construção da família. Revista Cidade Solidária, 2004 [online], 11, 6-23. Acesso em 28 de janeiro de 2020, em http://www.scml.pt/direscrita/media/revista/rev_11/rituais_familiares.pdf 
LUDKE, Menga. ANDRE, Marli E.D.A. A Pesquisa em educação: abordagens qualitativas.2. ed. Rio de Janeiro: E.P.U., 2013.

MARCONI, Marina. LAKATOS, Eva. M. Metodologia Científica. 5. ed. São Paulo: Atlas, 2011.

MINAYO, Maria da Conceição. S. (Org.). Pesquisa Social: Teoria, Método e Criatividade. Petrópolis: Vozes, 2001.

OLIVEIRA, Marta. K. Jovens e adultos como sujeitos de conhecimento e aprendizagem. Revista Brasileira de Educação, São Paulo, n. 12, p. 59-73, 1999.

PALOMO, Victor. Psicoterapia: um ritual de reinvenção de si. In: SOUZA, Elizeu C. de; ABRAHÃO, Maria Helena M. B. de. (Org.). Tempos, narrativas e ficções: a invenção de si. Porto Alegre: EDIPUCRS: EDUNEB, 2006.

PINTO, Álvaro Vieira. Sete lições sobre educação de adultos. 12. ed. São Paulo: Cortez, 2001.

POIRIER, J.; CLAPIER-VALLADON, S.; RAYBAUT, P. Histórias de vida: teoria e prática. Lisboa: Celta, 1999 .

RODRIGUES, Roberto. Fundamentos da Logoterapia - na clínica psiquiátrica e psicoterapêutica. Petrópolis: Vozes, 1991. v. 1.

SERRA, Deuzimar Costa. Gerontagogia Dialógica Internacional. Fortaleza: Edições UFC, 2015.

SILVA, Francisca de Paula Santos da (Org.). Turismo de base comunitária e cooperativismo: articulando pesquisa e ensino no Cabula e entorno. Salvador: EDUNEB, 2013.

SOUZA, Elizeu Clementino de. Diálogos cruzados sobre pesquisa (auto)biográfica: análise compreensiva-interpretativa e política de sentido. Educação - Revista do Centro de Educação, Santa Maria, v. 39, n. 1, p.39-50, 2014.

SOUZA, Elizeu Clementino de. (Auto)biografia e documentação narrativa: redes de pesquisa e formação. Salvador: EDUFBA, 2015.

SOUZA FILHO, Alcides Alves de. Educação de Jovens e Adultos: educação da pessoa e processo socioeducativo na Universidade Aberta à Terceira Idade. 2019. 199 f. Dissertação (Mestrado) Programa de Pós-Graduação em Educação de Jovens e Adultos, Universidade do Estado da Bahia, Departamento de Educação do Campus I, Salvador, BA, 2019.

SOUZA, Elizeu Clementino de; SOUSA, Rosiane Costa de. Condições de trabalho docente, classes multisseriadas e narrativas de professoras no território do baixo sul baiano: significados e sentidos. Currículo sem Fronteiras, v. 15, n. 2, p. 380-408, mai.-ago., 2015. 


\section{Dados dos autores}

\section{Alcides Alves de Souza Filho}

Mestre em Educação de Jovens e Adultos. Secretaria de Educação do Estado da Bahia. Professor da Rede Estadual de Ensino. Grupo de Pesquisa Gestão, organização, tecnologia e políticas públicas na educação básica da Bahia (GEPE/UNEB) Departamento de Educação da Universidade do Estado da Bahia. E-mail: alcisofilho@hotmail.com LATTES iD http://lattes.cnpq.br/0353684132153514.

\section{Antonio Amorim}

Professor Titular Pleno do Departamento de Educação do Campus I da Universidade do Estado da Bahia - UNEB, atuando no Mestrado em Educação de Jovens e Adultos. Tem Doutorado em Psicologia pela Universidade de Barcelona - Espanha. E-mail: amorimrho25@yahoo.com.br LATTES iD http://lattes.cnpq.br/9993429400708011.

\section{Kátia Siqueira de Freitas}

Pós-doutora em Administração da Educação, Professora e pesquisadora da Universidade Católica de Salvador. E-mail: sfkatia@gmail.com ORCID iD https://orcid.org/0000-0003-0984-814X. 